\title{
INCLUSÃO ESCOLAR DE ALUNOS COM DEFICIÊNCIA NA REDE MUNICIPAL DE SÃO LUÍS
}

Paulo Roberto de Jesus Silva'

Mariza Borges Wall Barbosa de Carvalho²

\section{RESUMO}

A construção de uma educação democrática no país é uma questão fundamental para romper com o histórico processo de segregação e exclusão dos alunos público-alvo da Educação Especial. Nesse processo, as redes públicas municipais de educação encontram-se no centro das atenções, por serem as responsáveis prioritárias do Ensino Fundamental, etapa da Educação Básica na qual se concentra o maior número de matrículas desses alunos nas classes comuns. Assim, a Rede Pública Municipal de Educação São Luís-MA, lócus desta pesquisa, encontra-se no bojo da questão. Destarte, reflete-se sobre o processo de organização da política educacional para atender as exigências acentuadas pelo movimento de inclusão escolar desse alunado, movimento este imbricado com a própria dinâmica política pedagógica da SEMED de São Luís. Este estudo tem como objetivo central investigar sobre a estruturação da Política de Educação Especial da referida Rede Municipal no contexto de uma inclusão escolar. Para tanto, compreende-se como coerente esboçar um ensaio teórico a partir da revisão de literatura com aporte nas contribuições de autores de referência na área, bem como num diálogo profícuo com pesquisas em níveis de pós-graduação que anteriormente analisaram a referida Rede, bem como lança-se um olhar curioso e analítico sobre alguns dos mais relevantes documentos oficiais

1 Professor do Instituto Federal de Educação, Ciência e Tecnologia do Maranhão. Mestre em Educação pelo Programa de Pós-Graduação em Educação/UFMA. Doutorando em Educação em Ciências e Matemática/REAMEC/POLO UFPA. E-mail: paulo.educador3@gmail.com.

2 Professora do Departamento de Educação ll e do Programa de Pós-Graduação em Educação da Universidade Federal do Maranhão. Coordenadora do Grupo de Pesquisa em Educação Especial. Doutora em Educação pela Universidade Metodista de Piracicaba. E-mail: mariwall@uol.com.br. 
da Prefeitura local que versava sobre sua política de educação. Por fim, ousa-se realizar uma crítica sobre a dinâmica de constituição da política municipal de educação especial/inclusiva na perspectiva de contribuir na superação da segregação e exclusão que tem marcado a educação de importantes parcelas estudantis.

Palavras-Chave: Educação Especial. Política Educacional. Inclusão Escolar.

\section{SCHOOL INCLUSION OF STUDENTS WITH DISABILITIES IN THE MUNICIPAL NETWORK OF SÃO LUIS}

\section{ABSTRACT}

The construction of a democratic education in the country is a key issue to break with the historical process of segregation and exclusion of the target audience of Special Education students. In this process, the municipal education public networks are in the spotlight, to be the priority in charge of Basic Education, Basic Education stage in which the largest number of enrollments of these students in regular classes. Thus, the Municipal Public Network São Luís-MA Education, locus of this research lies in the core of the matter. Thus, reflected on the process of organizing the educational policy to meet the requirements marked by the movement of school inclusion of these students, moving this imbricated with the dynamics educational policy of São Luís - SEMED. This study has as main objective to investigate on the structuring of the Special Education Polic at the mentioned Municipal Network in the context of a school inclusion. Therefore, we understand how coherent sketch a theoretical essay from the literature review with input on the contributions of authors of reference in the area, as well as a fruitful dialogue with research in graduate levels previously analyzed at the mentioned network and launches If a curious and analytical look at some of the most relevant official documents of the local municipality which was about his education policy. Finally, we dare to carry out a 
critique of the dynamics of formation of municipal policy of special / inclusive education in order to contribute in overcoming segregation and exclusion that has marked the education major student installments.

Keywords: Special Education. Educational policies. School inclusion.

\section{INCLUSIÓN ESCOLAR DE ALUMNOS CON DISCAPACIDADE EN LA RED MUNICIPAL DE SÃO LUIS}

\section{RESUMEN}

La construcción de una educación democrática en el país es una cuestión fundamental para romper con el histórico proceso de segregación y la exclusión de los alumnos público objetivo de la Educación Especial. En este proceso, las redes públicas municipales de educación se encuentran en el centro de las atenciones, siendo responsables prioritarias de la Enseñanza Fundamental, etapa de la Educación Básica, en la cual se concentra el mayor número de matrículas de estos estudiantes en las clases regulares. Así, la Red Pública Municipal de Educación de Sao Luis-MA, locus de esta investigación, se encuentra en el núcleo de la cuestión. Así, se refleja sobre el proceso de organización de la política educativa para cumplir con los requisitos marcados por el movimiento de la inclusión escolar de estos alumnos, movimiento este imbricado con la propia dinámica política pedagógica de la SEMED de São Luís. Este estudio tiene como objetivo central investigar la estructuración de la política de Educación Especial de la dicha Red Municipal en el contexto de una inclusión escolar. Para tanto, se comprende como coherente esbozar un ensayo teórico a partir de la revisión de la literatura con el aporte en las contribuciones de autores de referencia en la área, así como en un diálogo rentable con investigaciones en niveles de pos graduación que previamente analizaron la dicha Red, bien como se lanza una mirada curiosa y analítica en algunos de los más relevantes documentos oficiales del ayuntamiento sitio que versaba acerca de su política de educación. Por último, se atreve llevar a cabo una crítica de la dinámica 
de constitución de la política municipal de educación especial / inclusiva a fin de contribuir en la superación de la segregación y la exclusión que ha marcado la educación de importantes cuotas estudiantiles.

Palabras clave: Educación Especial. Política Educativa. Inclusión Escolar.

\section{Introdução}

O acesso dos alunos com deficiência, transtornos globais de desenvolvimento e altas habilidades ${ }^{3}$ às classes comuns das escolas públicas brasileiras tem ocorrido mais intensamente no ensino fundamental. Destaca-se que esse fluxo de matrículas, concentra-se nas séries iniciais do ensino fundamental o que possui relevante vínculo com a histórica falta de oportunidades educacionais que a maioria desses alunos têm para acessar os níveis mais elevados do ensino, ficando segregados em escolas e classes especiais que, geralmente, sequer possuíam seriação ou uma perspectiva de continuidade escolar (aos níveis mais elevados do ensino) sob o pretexto de uma "preparação" para ingresso no ensino comum, situação que só ampliava as limitações de possibilidades do desenvolvimento das potencialidades de cada um. $O$ ingresso de tais educandos em classes comuns das escolas públicas revela as fragilidades da escola pública, mas contraditoriamente aponta para a possibilidade de se enfrentar o modelo educacional excludente, também por meio da responsabilização do Poder Público com esse sistema de educação, desvelando as condições sociais e históricas que geram barbárie.

Considerando que, a Rede Pública Municipal de Educação de São Luís encontra-se no bojo desse cenário, justifica-se sua escolha para ser o foco do estudo deste trabalho, emergindo a seguinte problemática: como se estrutura a política de educação da SEMED/ São Luís, em especial, no que diz respeito à formação continuada, para

3 Terminologia utilizada tendo como referência Política de Educação Especial na Perspectiva da Educação Inclusiva (BRASIL, 2008). 
atender aos desafios da inclusão escolar dos alunos público-alvo da Educação Especial? Assim, compreende-se como objetivo investigar a organização da educação escolar de alunos com deficiência, transtornos globais de desenvolvimento e altas habilidades ou superdotação na estrutura da Secretaria Municipal de Educação de São Luís, especialmente no âmbito da Superintendência da Área de Educação Especial (setor responsável por esta modalidade).

Para percorrer esse caminho, utiliza-se como recurso metodológico a sistematização de ensaio teórico a partir da revisão de literatura, especialmente com base em pesquisa na pós-graduação e análise de documentos oficiais da Prefeitura Municipal de São Luís tais como: o Projeto de implantação do Programa "São Luís Te Quero Lendo e Escrevendo" (PSLTQLE) (SECRETARIA MUNICIPAL DE EDUCAÇÃO, 2003), Plano Decenal Municipal de São Luís (SECRETARIA MUNICIPAL DE EDUCAÇÃO, 2004), a Proposta Curricular (SECRETARIA MUNICIPAL DE EDUCAÇÃO, 2007), Relatórios de atividades da Secretaria de Educação, e informações disponíveis no site oficial da Prefeitura Municipal de São Luís, entre outros, além desses documentos, o diálogo com outras pesquisas.

\section{A organização da educação especial/inclusiva na rede municipal de} São Luís

As iniciativas pioneiras de escolarização de alunos com deficiência, transtornos globais de desenvolvimento e altas habilidades ou superdotação na rede pública municipal de São Luís, datam de 1984, porém neste episódio a experiência ocorreu de forma isolada e não oficial. Somente após dez anos (1994), houve ações oficiais nessa direção através do convênio 914/93 MEC/FNDE 4 /SEMED, no qual a Secretaria propôs implantar serviços de apoio aos alunos público-alvo da Educação Especial na referida rede de ensino (MELO, 2008; ALCÂNTARA, 2011). Este processo de implantação foi impactado pelo movimento das políticas

4 Fundo Nacional de Desenvolvimento da Educação. 
educacionais dos anos 1990, no sentido de municipalizar o Ensino Fundamental, cuja repercussão na Educação Especial deu-se por meio de significativo crescimento de matrícula em diversas redes municipais no Brasil (PRIETO, 2006). Movimento que ocorreria tardiamente na realidade maranhense, visto que ainda eram as instituições privadas que representavam significativo quantitativo da oferta de vagas aos alunos público-alvo da Educação Especial (CARVALHO, 2008).

Constata-se que o percurso histórico da Educação Especial naSEMED de São Luís imbrica-se com um movimento de lutas e conquistas por espaços (MELO, 2008). Sendo necessário o estabelecimento de estratégias de resistência do setor de Educação Especial em relação ao isolamento imposto pela própria Secretaria de Educação. Resistência que se fragilizava em decorrência do reduzido número de profissionais especializados que atuavam no setor, no qual precisavam se desdobrar para atender as crescentes solicitações oriundas das escolas da Rede municipal dispersas nas zonas rurais e urbanas e ao mesmo tempo ocupar os espaços de deliberação política e pedagógicas constituídas na SEMED, sob o constante risco de esquecimento e exclusão das questões ligadas à Educação Especial. Some-se ainda que, essa equipe via-se obrigada a mesclar dupla atribuição: "[...] agregavam ora a função destinada à equipe técnica interdisciplinar, ora as funções de professor especializado" (MELO, 2008, p.55).

Em 2002, a Educação Especial local encontrava-se diante de uma nova política da SEMED intitulada de "Programa São Luís Te Quero Lendo e Escrevendo" (PSLTQLE) que, segundo a própria Secretaria de Educação, objetivava "implantar a política de formação continuada dos educadores [...] (SECRETARIA MUNICIPAL DE EDUCAÇÃO, 2003, p. 25). Por sua vez Prazeres (2008) afirma que na constituição dessa nova estratégia política a SEMED seguiu o receituário neoliberal postulado em diretrizes internacionais forjadas pelos organismos multilaterais como Fundo Monetário Internacional (FMI), Organização das Nações Unidas para a Educação, a Ciência e a Cultura (UNESCO), Fundo das Nações Unidas para a Infância (UNICEF) e Banco Mundial. 
A SEMED, argumentou que os motivos que impulsionaram a implantação de um programa de reestruturação de toda a secretaria emergiram a partir do contexto no qual os maiores problemas da Educação não recaíam sobre a carência de investimentos, mas focavamse na ordem da gestão e planejamento com um claro aceno para uma perspectiva do gerencialismo na gestão da escola pública.

Apesar do discurso oficial, apresentar uma suposta centralidade dos processos formativos em todos os eixos estratégicos do Programa São Luís Te Quero Lendo e Escrevendo, Melo (2008) aponta que a Empresa de Consultoria, contratada pela Prefeitura para assessorar as equipes da Secretaria de Educação, não englobou, em seu planejemento e ações, mecanismos teórico-metodológicos necessários para o avanço conceitual da proposta da Política de inclusão escolar já em andamento na rede, especialmente no que se tratava da escolarização e do atendimento educacional especializado ${ }^{5}$ dos alunos público da Educação Especial.

Houve assim um distanciamento da denominada macro política educacional da Secretaria Municipal de Educação com a perspectiva inclusiva do setor de Educação Especial, na medida em que esta empresa ao concentrar as orientações/decisões sobre as novas diretrizes de organização para mudanças nas concepções e práticas educacionais a serem implantadas nas escolas da rede municipal, não incluiu coerentemente as necessárias mudanças para responder as especificidades e complexidades da Educação Especial.

Concepções estas que muitas vezes atribuiam quase que exclusivamente as causas do fracasso escolar aos próprios alunos público-alvo da Educação Especial sob alegação das limitações impostas pela deficiencia, e, em alguns casos, pela culpabilização das famílias e/ ou as escolas anteriores.

5 Conjunto de atividades, recursos de acessibilidade e pedagógicos organizados institucional e continuamente, prestado de forma complementar à formação dos estudantes com deficiência, transtornos globais do desenvolvimento, como apoio permanente e limitado no tempo e na frequência dos estudantes às salas de recursos multifuncionais; ou suplementar à formação de estudantes com altas habilidades ou superdotação (BRASIL, 2009). 
Neste sentido, a equipe de Educação Especial demonstrava ter clareza que apenas suas intenções não seriam suficientes para modificar as concepções e práticas instaladas e fortalecidas na Secretaria. Assim, a então chefe da Superintendência de Área de Educação Especial, a partir do início da gestão do Secretario Municipal de Educação da época (2002), decidiu diversificar a forma de ação da SAEE.

Conscientes de que a Educação Especial não avançaria, se continuasse numa paralela em relação aos níveis de ensino, esta professora relata que tirou proveito do espaço político conquistado na gestão do então Secretário de Educação. Este posicionamento encontrou espaços positivos, a princípio, no percurso de elaboração de dois documentos que norteariam as ações da rede: o Plano Decenal e a Proposta Curricular da Secretaria Municipal de Educação. (MELO, 2008, p. 48).

Com esta ocupação de espaços se favoreceu a oportunidade de inserir o conceito de inclusão escolar na Proposta Curricular da referida rede, convergindo com a ideia de uma escola democrática. Pois, essa esta deveria estar "[...] comprometida com o sucesso dos/as alunos/ as e toma a si a tarefa de mobilizar todos os sujeitos e todos os espaços a fim de garantir que todos aprendam num processo contínuo de avanço e progressão na construção do conhecimento" (SECRETARIA MUNICIPAL DE EDUCAÇÃO, 2007, p. 33). Também no Plano Decenal Municipal de Educação, construído para o período de 2004 a 2013, reconhece-se o processo de municipalização implantado nas redes públicas municipais do país ${ }^{6}$ exigindo a reorganização da Educação na esfera local (LEITE, 2006).

Especificamente no que diz respeito à Educação Especial, tal plano aponta para várias necessidades, dentre elas, a de identificar o perfil de seu alunado, inclusive com o levantamento das necessidades educacionais específicas de forma a subsidiar a oferta de respostas de

6 Considerando que no Nordeste, inclusive no Maranhão já havia uma concentração de matrículas do ensino fundamental. 
qualidades às demandas postas (SECRETARIA MUNICIPAL DE EDUCAÇÃO, 2004). No que diz respeito a esta questão exigiram-se ações formativas no âmbito da equipe multiprofissional da SAEE, pois compreendia a identificação do alunado da Educação Especial como um levantamento das necessidades educacionais específicas de cada sujeito no âmbito de uma abordagem social da deficiência e não médica como era geralmente cobrada por muitos profissionais da educação da rede que focavam sua atenção nas limitações orgânicas do aluno, exigindo um laudo clínico para direcionar as práticas escolares, numa clara postura heterônoma em relação ao processo de ensino e aprendizagem.

Cabe ressaltar que o Plano Decenal de Educação local (2004-2013) explicitava ainda, que os serviços e programas da Educação Especial se constituiriam sobre os princípios de inclusão do alunado da Educação Especial por meio do "[...] acesso ao saber socialmente construído e a conquista da autonomia social, moral e intelectual, fundamentos para o exercício da cidadania e transformação da realidade social" (SECRETARIA MUNICIPAL DE EDUCAÇÃO, 2004, p. 71). Autonomia que é indispensável na luta contra todas as formas de bárbarie e discriminação (ADORNO, 2010). Para tanto, deve-se enfrentar quaisquer dissociações entre Ética e a capacidade de reflexão/ação sobre si mesmo e sobre a própria realidade, como se infere de Freire (2010, p. 59):

\footnotetext{
O respeito a autonomia e dignidade de cada um é um imperativo ético e não um favor que podemos ou não conceder uns aos outros. Precisamente porque éticos não podemos desrespeitar a rigorosidade da ética e resvalar para sua negação, por isso é imprescindível deixar claro que a possibilidade do desvio do ético não pode receber outra designação senão a de transgessão.
}

Nesta perspectiva ética, a autonomia das pessoas com deficiência vem se fortalecendo pelo constante aprimoramento dos seus movimentos sociais. Neste sentido, Lima, Silva e Silva (2005) destacaram que na constituição e representação dos fóruns e conselhos gestores, normativos e consultivos das Políticas correspondentes às crianças e 
adolescentes com deficiência, em São Luís, já existia uma participação cada vez mais sistemática da sociedade civil. Constata-se que esses movimentos têm avançado, a medida em que superam equívocos conceituais, políticos e práticos sobre direitos em contraposição à práticas assistencialistas uma vez que os movimentos sociais pautam suas lutas na equiparação de oportunidades e respeito as especificidades e cidadania de cada um e não em privilégios e regalias (SANTOS; SILVA, 2010). Estas diversas formas de participação são legítimas e indispensáveis, respaldando-se na concepção de democracia que se contrapõe a barbárie (NAJJAR; FERREIRA, 2009).

Nesta direção, objetivando assegurar o acesso ao saber e avanços na autonomia dos estudantes com deficiencia matriculados nas escolas da Rede Municipal de São Luís, a SAEE constituiu serviços e programas da Educação Especial que se materializavam por meio de Avaliação Psicopedagógica ${ }^{7}$, Sala de Recursos Multifuncionais, Classe Especial, Equipe Interdisciplinar, Acompanhamento Itinerante ${ }^{8}$, Atendimento Domiciliar, Educação Profissional, Professor intérprete, Instrutor de Libras, Instrutor de Braille, Acompanhamento às escolas e Formação continuada em Educação Especial (SECRETARIA MUNICIPAL DE EDUCAÇÃO, 2008). Porém, ainda que a Sala de Recursos fosse considerada o lócus primordial na oferta dos atendimentos educacionais especializados, constatou-se um distanciamento entre a concepção defendidas nos documentos oficiais adotados e as práticas desenvolvidas nas salas de recursos (MELO, 2008).

Os documentos oficiais da SEMED já citados apontavam para um processo de "Ressignificação de $100 \%$ das classes especiais na área da surdez, da Deficiência intelectual, Deficiência Visual e transtornos globais de desenvolvimento" (SECRETARIA MUNICIPAL DE EDUCAÇÃO, 2004, p.78). Este processo seria concretizado na rede com a quase eliminação desse modelo de classes, excetuando-se as ligadas à

7 Processo realizado por equipe multidisciplinar responsável por levantar as necessidades educacionais específicas da população alvo da Educação Especial.

8 Serviço de apoio à inclusão, realizado por professor especializado em uma das áreas da Educação Especial, junto às escolas que possuem alunos com deficiência matriculados no ensino comum. 
área da surdez e do autismo. Parece razoável conceber que essa extinção se expressa na possibilidade da SAEE ter adotado imediatamente as orientações/determinações do Ministério da Educação no sentido de tornar obrigatória a matrícula dos alunos com deficiência nas classes comuns.

Isto pode indicar, também, uma adesão cega da SAEE aos dispositivos nacionais em evidência no momento, sem ter havido um processo mais estruturado para uma (auto)reflexão institucional e da própria equipe de Educação Especial, com protagonismo das escolas da rede no que se refere aos múltiplos desenhos da organização da Educação Especial no âmbito nacional e local, de forma a problematizar a partir da complexidade e especificidades de cada área, apontando para possibilidades de transição de um modelo ao outro.

Destarte, enquanto o número de alunos com deficiência nas classes especias se esvanecia, os dados de matrículas no ensino comum acompanhavam a tendência nacional de crescimento como se pode observar no mapa da evolução das matrículas sinalizado na Tabela 1.

Tabela 1 - Número de matrículas na Educação Especial da Rede Pública Municipal de São Luís segundo modalidade de atendimento $1998-2010$

\begin{tabular}{|c|c|c|c|c|c|c|c|c|c|c|c|c|c|}
\hline Anos & 1998 & 1999 & 2000 & 2001 & 2002 & 2003 & 2004 & 2005 & 2006 & 2007 & 2008 & 2009 & 2010 \\
\hline $\begin{array}{c}\text { Classe } \\
\text { Especial }\end{array}$ & 107 & 193 & 212 & 224 & 232 & 340 & 382 & 430 & 385 & 298 & 337 & 260 & 159 \\
\hline $\begin{array}{c}\text { Sala de } \\
\text { Recurso }\end{array}$ & - & 07 & 12 & 28 & 187 & 187 & 240 & 187 & 251 & $*$ & $*$ & $*$ & 655 \\
\hline $\begin{array}{c}\text { Classe } \\
\text { Comum }\end{array}$ & - & 07 & 12 & 28 & 289 & 384 & 697 & 1203 & 1372 & 1083 & 1272 & 1585 & 1758 \\
\hline Total & 107 & 200 & 224 & 252 & 521 & 724 & 1079 & 1633 & 1757 & 1381 & 1609 & 1845 & 1917 \\
\hline
\end{tabular}

Fonte: Coordenação de Documentação e Estatística da SEMED - São Luís.

NOTA (1): Para o cômpute total de alunos atendidos não se incluem na somatória as matrículas em "Sala de Recurso", visto que os alunos desse atendimento já estão inseridos no item "Classe Comum". 
NOTA (2): Os dados de matrículas nas Salas de Recursos no período de 2007 a 2009 não foram informados.

Constata-se que, do ano de 2001 para 2002, o número de alunos público-alvo da Educação Especial em Classe Comum ampliou-se em mais de 10 (dez) vezes, saltando de 28 para 289 alunos (representando $11 \%$ e $55 \%$ do número total de matrículas da Educação Especial). Esse crescimento pode se relacionar com uma determinação mais firme estabelecida pela Resolução № 01/2001 CNE/CEB. O ingresso dos alunos com deficiência, transtornos globais de desenvolvimento e altas habilidades ou superdotação no ensino comum da rede municipal de São Luís seguiu sua trajetória de crescimento cujo pico, no período, ficou expresso nos números de 2009 e 2010, correspondendo respectivamente a $86 \%$ e $91 \%$ das matrículas totais da Educação Especial. Por sua vez as matrículas nas Salas de Recursos, mesmo demonstrando avanço, ainda estavam aquém do necessário para cobertura de todos os alunos que teriam direito a esse serviço.

Dentre os principais argumentos alegados pela Superintendência de Educação Especial da SEMED sobre este déficit de matrículas nas Salas de Recursos estariam as decorrentes do número insuficientes de salas, distância geográfica das mesmas em relação à residência dos alunos; baixo nível de entendimento dos pais sobre o papel do atendimento educacional especializado e limitações do uso do passe livre considerando a vunerabilidade socioeconômica de várias famílias (SECRETARIA MUNICIPAL DE EDUCAÇÃO, 2008). Por sua vez, Melo (2008, p.74) acrescenta a esses argumentos, problemas relacionados a credibilidade, por parte da família, na contribuição efetiva da sala de recursos no desempenho dos filhos, falta de correspondência das respostas da equipe técnica as necessidades escolares e questões concernentes à fragilidade na fundamentação teórica metodológica que requer a temática.

Este descompasso do acesso entre as classes comuns e as salas de recursos implica em uma maior fragilidade do processo de inclusão escolar dos alunos público-alvo da Educação Especial, uma vez que se compreende como indispensável uma qualitativa 
relação de complementaridade (alunos com deficiência ou transtornos globais do desenvolvimento) ou suplementaridade (alunos com alta habilidade ou superdotação) entre estes lócus para a formação integral e inclusiva do sujeito. Questão fundamental para atendimento das necessidades educacionais básicas e específicas do alunado, na medida em que o projeto pedagógico da escola precisa garantir a oferta dos atendimentodo educacionais específicos articulados com o processo de escolarização. Cabe ressaltar que é necessário investir em pesquisas que investiguem estas relações entre o AEE e o ensino comum possibilitando uma maior articulação epistemológica e prática entre estes dois campos.

No que se refere aos números totais de matrículas do alunos público-alvo da Educação Especial quando confrontados com o montante de matrículas da rede municipal de São Luís, conforme Tabela 2 , observa-se a mesma problemática, encontrada nacionalmente ${ }^{9}$, isto é, a baixa cobertura do Poder Público sobre as demandas escolares desse alunado. Pois, as matrículas dos alunos público-alvo da Educação Especial nas escolas da Rede Pública Municipal de São Luís correspondiam a menos de $2 \%$ do total na referida rede (1,83\%, em 2009 e 1,72\%, em 2010), realçando, assim, um dos grandes desafios da Educação Especial no Brasil, e especialmente em São Luís, de crescer numericamente e com qualidade.

Tabela 2 - Relação número de matrículas gerais e específicas na rede municipal de São Luís ${ }^{10}$

\begin{tabular}{|c|c|c|c|}
\hline Ano & 2009 & 2010 & $\begin{array}{c}\text { Evolução 2009- } \\
2010(\%)\end{array}$ \\
\hline Matrícula geral da rede & 100.314 & 111.458 & 11 \\
\hline $\begin{array}{c}\text { Matrícula específica da } \\
\text { Educação Especial }\end{array}$ & 1.845 & 1917 & 10 \\
\hline
\end{tabular}

Fonte: Prefeitura Municipal de São Luís

9 Do total de 51.549.889 matrículas em toda a Educação Básica brasileira, em 2010, apenas $1,3 \%$ dizia respeito aos alunos com deficiência, transtornos globais de desenvolvimento e altas habilidades. Esse índice era de 1,2\% em 2009.

10 Tabela criada pelos autores a partir dos dados disponíveis da Prefeitura Municipal de São Luís. 
Diante desses e outros desafios, bem como implicações oriundas da mudança na gestão municipal, no ano de 2009, a SEMED implantou uma nova macropolítica educacional denominada de Programa São Luís "Cidade que Educa e Aprende" (PSLCEA). Tal Programa, no seu ano inaugural, manteve uma organização similar a anterior, sendo composta pelos seguintes eixos gerenciais "Formação Continuada, Avaliação, Gestão e Rede Social Educativa", cujo objetivo consistia em "Garantir acesso, permanência e sucesso escolar de todas as crianças, jovens e adultos atendidos pelo sistema municipal de ensino" (SECRETARIA MUNICIPAL DE EDUCAÇÃO, 2010, p.07). Dentre os príncipios dessa política encontravam-se as relacionadas a: Gestão Democrática; Gestão Participativa; Igualdade de Condições; Valorização do Magistério; Inclusão; Liberdade; Transparência; Solidariedade e Valorização do Ser Humano.

Neste cenário, a SEMED de São Luís possuía 170 escolas (Unidade de Educação Básica) e aproximadamente 60 anexos ${ }^{11}$, sendo que em $72 \%$ destas escolas já haviam registrado matrículas de alunos da Educação Especial. Dentre as 170 escolas, a maioria encontrava-se parcialmente adaptada arquitetonicamente, correspondendo a $88 \%$ das escolas de Ensino Fundamental/Educação de Jovens e Adultos e 54\% de Educação Infantil. Ainda no que se refere às “[...] exigências para a escola inclusiva e que respeite a diversidade" a SEMED elegeu oficialmente a Formação Continuada dos profissionais da Educação como um dos eixos centrais para alcançar uma "Educação de Qualidade para Todos" assegurando "conhecimentos necessários para a construção de uma escola pública de qualidade" (SECRETARIA MUNICIPAL DE EDUCAÇÃO, 2010, p.30).

Esse entendimento de escola pública de qualidade, pelo menos no discurso, se coaduna com a perspectiva de construção de uma inclusão escolar para além da matrícula como enfatiza Glat e Blanco

11 A maioria dos anexos das escolas possuía precárias condições de funcionamento que iam desde a falta de gestores e/ou coordenadores locais até graves comprometimentos em suas infraestruturas, principalmente nas reduzidas e desconfortáveis salas de aula, muitas vezes lotadas de cadeiras velhas e alunos. Algumas não tinham sequer paredes dividindo as salas, mas precários improvisos. 
(2009, p. 17-18) que o “[...] objetivo desta proposta é a possibilidade de ingresso e permanência do aluno na escola com sucesso acadêmico, e isso só poderá se dar a partir da atenção às suas peculiaridades de aprendizagem e desenvolvimento". Mediante esse entendimento é possível reconhecer o lugar estratégico, e não suficiente, da formação continuada na construção de escolas que incluam todos os alunos. Devendo-se atentar também para as demais questões de infraestrutura que se desdobram de um projeto de inclusão escolar com democracia e emancipação. Dentre elas a valorização dos profissionais da educação.

Desta forma, cabe ressaltar que, especificamente no bojo da SEMED, as formações continuadas estavam subordinadas diretamente à Secretaria Adjunta de Ensino ou às Superintendências e Coordenações de cada nível ou modalidade de ensino. Dentre as formações promovidas diretamente pela Secretaria Adjunta de Ensino e que tinham implicações importantes também nas práticas educacionais voltadas para a inclusão escolar (não somente dos alunos público-alvo da Educação Especial) destacava-se a realizada junto aos coordenadores pedagógicos das escolas. Estas formações de coordenadores objetivavam promover discussões sobre a realidade de cada escola da rede. Assim, suas pautas deveriam emergir das inquietações e experiências dos participantes e como consequência surgiriam as temáticas e metodologias a serem abordados nas formações continuadas de cada unidade de educação básica.

Alcântara (2011) compreendeu que estas Formações, adotada pela SEMED, implicavam com os postulados neoliberais na medida em que focava no saber fazer e na resolução de problemas imediatos, ao passo que não se fomentava a problematização mais apurada da realidade de forma aprofundada. Nessa mesma direção Prazeres (2008, p. 137) compreende que a formação de coordenadores e professores se centrou em discussões sobre o cotidiano escolar sob a perspicácia de privilegiar seu modelo neoliberal de gestão:

[...] focaliza-se a gestão do cotidiano da sala de aula e da escola como um todo numa linguagem coerente 
com o modelo gerencial adotado. Privilegia-se o que acontece na sala de aula, sem relacioná-lo à escola como um todo e ao contexto social mais amplo. Ademais, verifica-se o abandono da categoria trabalho pelas categorias práticas ou prática reflexiva.

Dentre as formações promovidas pelas superintendências, a responsável pela Educação Especial foi a que registrou a maior participação de profissionais, com cerca de mil cento e sete participantes (1107), agregando um público diversificado (diretores das escolas, professores, coordenadores, especialistas e famílias). Estas formações movimentavam-se em três direções a saber:qualificação dos profissionais diretamente envolvidos nas atividades desenvolvidas nos atendimentos educacionais especializados; capacitação dos profissionais das escolas e sensibilização da comunidade em geral. A pretensão seria promover a "[...] construção de consenso da Educação Inclusiva" (SECRETARIA MUNICIPAL DE EDUCAÇÃO, 2004, p.79).

Esta pretensão de consenso reverte-se de preocupação, pois pode revelar novamente uma adesão cega e heterônoma a um único desenho da educação especial muitas vezes traçada distante da realidade ludovicense e, principalmente descolada das escolas locais; porém, é promissor um movimento formativo contínuo e ampliado numa perspectiva de esclarecimento e emancipação atores/autores da práxis educativa da rede municipal de São Luís.

Retornando a análise dos números sobre a formação no âmbito da SAEE, em relação ao seu expresso volume, pode-se encontrar uma explicação, que inclua pelo menos dois fatores complementares. Um seria a crescente exigência oriunda das escolas, principalmente no que se refere à operacionalização (saber fazer) da inclusão escolar, uma vez que o ingresso dos alunos público-alvo da Educação Especial nas escolas promovem debates, tensões, desafios e necessidades de mudanças no cotidiano escolar. Em muitos casos às solicitações de formações continuada se erguiam sob discurso da falta de preparação para ensino desta parcela estudantil (COSTA, 2009; FREITAS, 2010; ALCÂNTARA, 2011). Outro fator, que ajuda a entender o significativo 
número de participantes nas formações que versavam sobre educação especial, estava ligado às implicações teóricas metodológicas da opção da SAEE em matricular, quase que exclusivamente e imediatamente, todos os alunos público-alvo da Educação Especial nas classes comuns da rede municipal.

Estas formações, ainda que não fossem suficientes, emergiram em sintonia com o entendimento da equipe gestora da Educação Especial da rede pública municipal de São Luís, mantendo sua postura de luta por via da ocupação de espaços, ou aproveitando brechas, na própria dinâmica interna da Secretaria (MELO, 2008; SEVERINO, 2008).

No que tange a atuação da equipe SAEE nas escolas, destacam-se as relacionadas aos profissionais da educação - como orientações pedagógicas e acompanhamento especializado; e aos familiares dos alunos - por meio de visitas, atendimento e reuniões no sentido de fornecer aos pais ou cuidadores, saberes relacionados às pessoas com deficiência, transtornos globais de desenvolvimento e altas habilidades. E no que se refere aos demais espaços da comunidade, a equipe da SAEE, marcava presença nas discussões coletiva, como no caso do Conselho Municipal da Pessoa com Deficiência.

Dentre as metas da SAEE que se pretendia consolidar até 2012, ano de comemorações do quadricentenário da cidade de São Luís, podiam-se destacar as que diziam respeito à garantia de matrículas (no ensino regular) e acesso curricular aos alunos público-alvo da Educação Especial em $100 \%$ das escolas municipais, bem como a adaptação arquitetônica de $100 \%$ da Rede.

As metas citadas acima coadunam-se com a tendência nacional elocal de matricular todos os alunos com deficiência, transtornos globais de desenvolvimento e altas habilidades ou superdotação nas classes comuns do ensino regular. Como já analisado anteriormente, a SAEE decidiu desativar as classes especiais da rede municipal, com exceção daquelas na área do autismo e surdez. 
Contudo, a então meta oficial é de não haver mais exceções. Essa decisão certamente implica em acirradas disputas com alguns movimentos de pessoas com deficiência, dentre estas as relacionadas à área da surdez que advogam que as classes comuns não garantem o respeito às suas especificidades linguísticas, culturais e de identidade, requerendo salas e/ou escolas específicas. Por outro aspecto, a mudança do panorama segregador da Educação Especial representa uma importante contribuição no processo de democratização da Educação pública para essa parcela estudantil que tem sido historicamente abandonada pelo Poder Público e excluída pela sociedade.

\section{Conclusão}

A história da Educação Especial na rede pública municipal de São Luís ainda é recente, em cerca de duas décadas, desde o início oficial da oferta dos serviços especializados, sua trajetória imbrica-se diretamente com os percursos da Educação Especial no âmbito nacional, ressalvando suas especificidades locais.

No período investigado nesta pesquisa, um dos aspectos que se destacou foi a denominada "ressignificação" das classes especiais que representaria a eliminação deste tipo de serviço no âmbito da estrutura das escolas ligadas a SEMED de São Luís. Porém, esta mudança não tem se dado sem resistências, principalmente pelos profissionais que atuam na área da surdez sob o argumento das peculiaridades linguísticas dos estudantes surdos.

Neste cenário, observou-se uma virada nos dados da matrícula do público-alvo da Educação Especial que se concentrou no ensino comum numa íntima relação com as determinações de alguns dispositivos legais. Contudo, contraditoriamente, notou-se que a política de Educação Especial da SEMED ficou excluída, em parte, da estruturação advinda da denominada macropolítica municipal de educação uma vez que foi necessário enfrentamento da própria equipe da SAEE no sentido de garantir que as questões que envolvem a Educação Especial fossem consideradas nas discussões, documentos e ações institucionais. 
Ao passo em que a SEMED anunciava que a formação continuada seria uma das principais diretrizes para construção de escolas de qualidade para todos, contraditoriamente, notou-se que dentro da própria Rede Municipal de São Luís, o setor responsável pela Educação Especial precisa manter postura de vigilância para assegurar as condições mínimas de entendimento sobre a inclusão escolar na dinâmica da política municipal de educação.

Observou-se então que esta Rede de Educação vinha estruturando sua política de inclusão escolar a partir de embates internos e externos no âmbito de sua Secretaria de Educação. Nessa questão, o setor responsável pela Educação Especial viu-se na necessidade de lutar pela conquista de espaços políticos e administrativos em compasso com a perspectiva de dinamizar a organização dos atendimentos educacionais especializados em sintonia com o processo de escolarização dos alunos público-alvo da Educação Especial nas unidades escolares. Em um processo de sinergia teórica metodológica e político-pedagógica.

Nesta realidade acentuou-se as tensões e desafios referentes ao processo de inclusão escolar dos alunos público-alvo da Educação Especial. Processo que requer a construção de escolas que superem a manifestação do preconceito e valorize uma cultura escolar aberta a diversidade humana como uma possibilidade promissora do enfrentamento da barbárie presente em diversos ambientes colegiais.

Nessa direção, a luta histórica pelo acesso, permanência e sucesso escolar dos alunos com deficiência, transtornos globais de desenvolvimento e altas habilidades ou superdotação nas classes comuns das escolas públicas brasileiras constitui-se em um elemento relevante no processo de democratização da educação. Isso porque, a intensificação da oferta de matrículas (acesso) a este público implica em ampliação das problematizações sobre as condições objetivas, subjetivas e intersubjetivas relacionadas às escolas. Com isso, alimentase a esperança em mudanças na direção de avanços para transformar a escola em um espaço-tempo de aprendizagem, emancipação e humanização. 


\section{Referências}

ADORNO, Theodor W. Educação e emancipação. Rio de Janeiro: Paz e Terra, 2010.

ALCÂNTARA, Ramon L. S. A ordem do discurso na Educação Especial. 2011. 214 f. Dissertação (Mestrado em Educação). Universidade Federal do Maranhão, São Luís, 2011.

BRASIL. Política Nacional da Educação Especial na Perspectiva da Educação Inclusiva. Brasília, DF: MEC, 2008 . Resolução CNE/CEB no 4 de outubro de 2009. Brasília, DF: MEC, 2009.

CARVALHO, Mariza B. W. B. As peculiaridades da educação especial na política educacional do Maranhão (1997-2002). In: ALMEIDA, Maria Amélia; MENDES, Enicéia Gonçalves; HAYASHI, Maria Cristina P. I. (Org.). Temas em educação especial: múltiplos olhares. Brasília, DF: CAPES PROESP, 2008.

COSTA, Valdelúcia A. Políticas públicas de educação e formação de professores: experiências de inclusão dos alunos com deficiência na escola pública. In: CHAVES, Iduína Mont'Alverne; COSTA, Valdelúcia A. (Org.). Políticas públicas de educação: pesquisas em confluência. Niterói: Intertexto, 2009.

FREIRE, Paulo. Pedagogia da autonomia. Rio de Janeiro: Paz e Terra, 2010.

FREITAS, Maria G. F. Passos de tartaruga rumo à inclusão nas escolas: será descendemos de Jean Itard mais do que desejamos ou almejamos conviver menos com as diferenças educativas infantis em salas de aulas comuns? In: SILVA, Marilete G; CARVALHO, Mariza B. W. B.(Org.). Faces da Inclusão. São Luís: EdUFMA, 2010.

GLAT, Rosana; BLANCO, Leila M. Educação Especial no contexto de uma 
educação inclusiva. In: GLAT, Rosana (Org.). Educação inclusiva: cultura e cotidiano escolar. Rio de Janeiro: 7Letras, 2009.

LEITE, Zinole H. M. Inclusão Escolar de alunos com deficiência mental: entre o possível e o desejável. 2006. 217 f. Dissertação (Mestrado em Educação). Universidade Federal do Maranhão, São Luís, 2006.

LIMA, Terezinha M; SILVA, Maria J; SILVA, Selma M.M.M. Crianças e adolescentes com deficiência: direitos e indicadores de inclusão. São Luís: EDUFMA, 2005.

MELO, Hilce. $\mathbf{O}$ acesso curricular para alunos(as) com deficiência intelectual na rede regular de ensino: a prática pedagógica na sala de recursos como eixo para análise. 2008. 159 f. Dissertação (Mestrado em Educação). Universidade Federal do Maranhão, São Luís, 2008.

NAJJAR, Jorge; FERREIRA, Sueli C. Formação continuada, gestão escolar e construção da democracia no cotidiano da escola In: CHAVES, Iduína Mont'Alverne; COSTA, Valdelúcia A. (Org.). Políticas públicas de educação: pesquisas em confluência. Niterói: Intertexto, 2009.

PRAZERES, Valdenice A. Formação continuada de professores (as) no Programa São Luís Te Quero Lendo e Escrevendo: limites e possibilidades da reflexão sobre a prática. 2008. 299 f. Dissertação (Mestrado em Educação). Universidade Federal do Maranhão, São Luís, 2008.

PRIETO, Rosângela Gavioli. Atendimento escolar de alunos com necessidades educacionais especiais: um olhar sobre as políticas públicas de educação no Brasil. In: ARANTES, Valéria A. (Org.). Inclusão escolar: pontos e contrapontos. São Paulo: Summus, 2006.

SANTOS, Daniela B; SILVA, Luciene M. Formação e ação política no movimento social das pessoas com deficiência. In: CONGRESSO BRASILEIRO DE EDUCAÇÃO ESPECIAL, 4, São Carlos, 2010. Anais... São Carlos, 2010. 
SECRETARIA MUNICIPAL DE EDUCAÇÃO. Plano Decenal de Educação do Município de São Luís. São Luís, 2004.

. Projeto “São Luís Te Quero Lendo e Escrevendo”. São Luís, 2003.

. Proposta Curricular - marco conceitual. São Luís, 2007.

- Relatório da Superintendência da Área de Educação Especial - SAEE/2002-2008. São Luís, 2008.

10 Relatório quadrimestral DE 2010: ações desenvolvidas na Secretaria Municipal de Educação - SEMED. São Luís, 2010.

SEVERINO, A. J. Educação e inclusão. Revista de Educação Pública, Cuiabá, v. 17, n. 34, p. 227-235, maio/ago. 2008. 